\title{
Phobic nature of social difficulty in facially disfigured people
}

\author{
ROBERT NEWELL and ISAAC MARKS
}

\author{
Background Over 390000 people in \\ the UK are disfigured. Facial disfigurement \\ distresses sufferers markedly but has been \\ studied little.
}

\begin{abstract}
Aims To compare fearful avoidance of people with a facial disfigurement with that of a group of patients with phobia.
\end{abstract}

\section{Method Comparison of Fear}

Questionnaire agoraphobia, social phobia and anxiety depression sub-scale scores of II2 facially disfigured people (who scored high on Fear Questionnaire problem severity in three survey studies) with those of 66 out-patients with agoraphobia and 68 out-patients with social phobia.

Results Facially disfigured people and patients with social phobia had similar Fear Questionnaire scores. In contrast, facially disfigured people scored lower on the agoraphobia sub-score but higher on the social phobia sub-score than did patients with agoraphobia.

Conclusions Facially disfigured people with psychological difficulties resembled people with social phobia on Fear Questionnaire social phobia, agoraphobia and anxiety/depression sub-scores but were less agoraphobic and more socially phobic than were people with agoraphobia. Facially disfigured people thus appeared to be socially phobic and to deserve the cognitive-behavioural therapy that is effective for such phobias.

\section{Declaration of interest R. N. was} initially supported by the University of Hull and by the University of Leeds thereafter.
About 390000 people in the UK are said to be disabled by disfigurement from trauma, mutilating surgery, skin disease or birth defect (Martin et al, 1988). These Government statistics define disability loosely and there is little clear evidence to relate level of disfigurement to psychosocial disturbance (Rumsey, 1983), so the number of disabled people may be even higher because less severely disfigured people with disabling distress may not appear in the figures. Disfigured people have problems with social interaction (Macgregor, 1951, 1990; Rumsey, 1983; Malt \& Ugland, 1989) and are discriminated against (Houston \& Bull, 1994). Negative stereotyping of disfigured people begins in childhood (Rumsey, 1983) and continues into adulthood, where facially disfigured people meet repeated verbal abuse, disgust and pity from others (Macgregor, 1951, 1989).

\section{Shortcomings of previous studies of psychological difficulties in disfigurement}

Follow-up studies of the psychological difficulties of disfigured people are problematic (reviewed by Malt, 1981; Rumsey, 1983). Numbers are small and response rates low. Many of the studies followed up only serious burns sufferers, and the study groups were not divided into adults and children, or by cause of the burn (Malt, 1981). Much of the work was carried out with patients still awaiting or receiving treatment (Rumsey, 1983), who might be atypical because they might still have expectations of further improvement, further treatment or recurrence of symptoms. Studies often did not identify whether dysphoria was due to disfigurement, disability, post-traumatic stress or premorbid personality. Comparisons with the general population were rarely drawn.

\section{Emerging issues from previous studies}

Some issues have emerged. Of 70 burned adults followed up 3-13 years later, 23\% had impaired psychological adjustment and more severely injured people were more disturbed $(44 \%)$ than those with minor injuries $(16 \%)$ (Malt \& Ugland 1989). Of 42 burned adults, $21 \%$ needed psychological help 18 months later (Faber et al, 1987), and $30-40 \%$ of 45 discharged burns patients had severe psychological difficulties both six months and two years after discharge (Wallace, 1988).

None of the above studies noted the site of the burn. Facial involvement was the best predictor of difficulty in 23 burns patients (Williams \& Griffiths, 1991). More caseness (General Health Questionnaire (Goldberg \& Williams, 1991) and Hospital Anxiety and Depression Scale (Snaith \& Zigmond, 1994)) was found in 105 expatients who had received plastic surgery to the face than in general population samples (Newell, 1998). They were no longer in treatment and so might be regarded as more typical of facially disfigured people as a whole than are patients still in contact with services.

\section{Approaches to treatment}

Promising treatment for facial disfigurement involves appropriate social skills training (Feigenbaum, 1981; Partridge et al, 1994; Robinson et al, 1996). For example, in the social skills training package taught by the self-help group 'Changing Faces', subjects showed a modest fall in anxiety and a rise in confidence (Robinson $e t$ al, 1996), although there was no control group.

In a randomised controlled study, 106 disfigured people, who were offered a selfhelp leaflet, improved modestly but statistically significantly more than the no-treatment controls at three-month follow-up (Newell, 1998). The leaflet gave cognitive-behavioural advice regarding the need for exposure to social situations that were avoided following disfigurement (Newell, 1991, 1998). It noted that disfigured people may fear and avoid social situations because of anxiety about their appearance and other people's possible responses to them, but that these can be overcome, just as with responses to chronic back pain (Lethem et al, 1983) and to disturbed body image in eating disorders (Slade, 1994). 


\section{Rationale for the present study}

Qualitative accounts (Macgregor, 1951, 1979) and surveys (Wallace, 1988; Williams \& Griffiths, 1991; Newell, 1998) attest to disfigured people's problems in public and suggest the likely role of anxiety in maintaining them. The present study extends this work by comparing fear and avoidance in facially disfigured people with pretreatment scores of out-patients treated for agoraphobia or social phobia.

\section{METHOD}

The study compared facially disfigured people's reported avoidances with those of outpatients with agoraphobia and social phobia on the agoraphobia and social phobia sub-scores of the Fear Questionnaire. Since the Fear Questionnaire was described by Marks \& Mathews (1979), it has been widely used in clinical practice and research.

\section{Participants}

Facially disfigured people (25 men, 87 women) were drawn from surveys of dermatology patients, plastic surgery expatients and announcements in the media. The out-patients with agoraphobia (27 men, 39 women) and social phobia (28 men, 40 women) had exposure therapy at the Psychological Treatment Unit of the Maudsley Hospital and their pre-treatment Fear Questionnaire ratings were available on its computerised database; the patients with phobia were selected from this database using a random selection facility built into the database.

\section{Ethics}

For the disfigured people, ethical approval was gained from the relevant local ethics committees and from R.N.'s academic school's ethics committee. For the patients with phobia, ethical approval was not required for access to anonymised data.

\section{Measures}

The Fear Questionnaire comprises scales rated $0-8$, arranged as follows:

(a) Severity of the phobic difficulty that the patient wants treated (main problem).

(b) Global impact of the patient's problems (0-8 global phobia sub-score).

(c) Fifteen items about avoided situations, of which five concern agoraphobia, five social phobia and five blood- injury, yielding five-item agoraphobia, social phobia and blood-injury phobia sub-scores (each score range 0-40).

(d) Five items concerning anxiety and depression (anxiety/depression subscore, range 0-40).

The Fear Questionnaire has no formal cut-off point for 'caseness', but higher scores denote more pathology. Score 4 on the global phobia scale shows a sufficiently severe phobic problem to warrant treatment (Newell, 1998). For facially disfigured people, in the global phobia $0-8$ subscore the word 'problem' was substituted for 'phobia'. This modification was also used by Corney et al (1990) and forms the global problem severity score referred to in this paper. Re-validation of the Fear Questionnaire might be considered necessary in the light of this change, but it should be noted that validity studies of this muchused measure are, in any case, limited. Further validation of the Fear Questionnaire in both its original form and the modified form used in the present study would be valuable.

\section{Procedure}

Facially disfigured people were recruited from dermatology out-patient clinics, expatient lists of plastic surgeons and via the media. Subjects completed a wide range of measures of behavioural and psychological disturbance (Newell, 1998). They were included in the present study if they rated Fear Questionnaire global problem severity as 4 or more, so reaching a problem severity criterion commonly used for inclusion in treatment by behaviour therapists.

For patients with phobia, the following patient information was extracted from the computer database: age at entry into treatment, gender, diagnosis and pre-treatment scores on Fear Questionnaire global phobia (global problem severity score), agoraphobia sub-score, social phobia sub-score and anxiety/depression sub-score. These scores were compared with those of the facially disfigured subjects.

\section{Data analysis}

The current study predicts similarity between two groups. This is similar to an estimation of equivalence between two treatments and is problematic, particularly with relatively small sample sizes (Senn, 1993). It may, however, be possible to assert equivalence on the basis of no significant difference being found between the groups when the sample sizes are known to be sufficiently large to find such differences, provided that an adequate definition of equivalence is made beforehand (Gould, 1993).

The relevant power calculation is shown in Table 1. Conventional alpha $(5 \%)$ and beta $(80 \%)$ levels were used. In the absence of previous studies, the effect size calculation for the chosen sub-scores was based on the variance of scores of disfigured subjects eligible to enter the study and an assumption of clinical difference between the groups of 8 points on each sub-score, reflecting a difference of 1.6 on each item of each sub-score. A difference of $<2$ points is unlikely to be clinically important, so differences of this magnitude or less are an appropriately stringent test of equivalence. The advice of a medical statistician was sought in the design of the project and examination of the data.

This study's 112 facially disfigured people, 66 patients with agoraphobia and 68 patients with social phobia yielded enough power to detect between-group differences, except for the agoraphobia sub-score to distinguish patients with agoraphobia from facially disfigured people.

\section{RESULTS}

The agoraphobia and social phobia subscores of the Fear Questionnaire discriminated between patients with agoraphobia and social phobia using the numbers of subjects available in the present study. The anxiety/depression scale narrowly failed to show such a difference (Table 2). The likelihood of a type 2 error due to subjects being too few was thus small.

The facially disfigured group had an even greater female preponderance than did the patients with agoraphobia and social phobia, was older by nine years than these patients with social phobia and had slightly less problem severity than patients with agoraphobia or social phobia (Table $3)$.

To take into account potential interaction with the independent variables (facial disfigurement $v$. agoraphobia and $v$. social phobia), between-group agoraphobia and social phobia Fear Questionnaire sub-score differences were compared by analysis of covariance using problem severity as a covariate for facial disfigurement $v$. patients with agoraphobia and problem severity plus age as covariates for facial disfigurement 
Table I Minimum numbers necessary to detect differences between facially disfigured people and patients with agoraphobia or social phobia, where such differences are present, according to Fear Questionnaire sub-scales

\begin{tabular}{lll}
\hline Measure & Effect size & Required subjects per group \\
\hline $\begin{array}{l}\text { Comparisons between facially disfigured people } \\
\text { and patients with agoraphobia }\end{array}$ & \\
$\quad$ Agoraphobia sub-scale & 0.29 & 74 \\
Social phobia sub-scale & 0.36 & 47 \\
Anxiety/depression sub-scale & 0.32 & 60 \\
Comparisons between facially disfigured people & & \\
and patients with social phobia & & 50 \\
Agoraphobia sub-scale & 0.35 & 45 \\
Social phobia sub-scale & 0.37 & 60 \\
Anxiety/depression sub-scale & 0.33 & \\
\hline
\end{tabular}

All group size calculations allow for the different sizes of the groups in the study.

$v$. patients with social phobia. Gender as a dichotomous categorical variable is not generally recommended for consideration as a covariate (Munro \& Page, 1993) and so was entered into the analysis as a further independent variable for comparisons of facially disfigured people $v$. patients with agoraphobia and social phobia. The results are shown in Table 4.

There were no differences by gender on the agoraphobia $(F=0.32$, d.f. $=1, P=0.574$, NS) or social phobia sub-scores $(F=3.38$, d.f. $=1, P=0.068$, NS), nor any significant differences between facially disfigured people and patients with social phobia on social phobia, agoraphobia and anxiety/ depression scores. Compared with patients with agoraphobia, facially disfigured people had significantly less agoraphobic avoidance, more social phobic avoidance and similar anxiety/depression. Group mean differences were not clinically important (by the criteria suggested above) between the facially disfigured and social phobia groups. For facially disfigured $v$. agoraphobia groups, only the agoraphobia sub-score difference reflected group mean differences likely to be clinically important.

\section{DISCUSSION}

\section{Similarities between facially disfigured people and patients with agoraphobia}

Facially disfigured people had similar agoraphobic and social phobic avoidance and anxiety/depression to patients with social phobia, with similar global problem scores. They differed from patients with agoraphobia in having less agoraphobic avoidance but more social phobic avoidance,

Table 2 Fear Questionnaire agoraphobia, social phobia and anxiety/depression sub-scales: comparisons between patients with social phobia or agoraphobia

\begin{tabular}{|c|c|c|c|c|c|}
\hline Scale & Critical value & d.f. & Significance & Group means & $95 \% \mathrm{Cl}$ \\
\hline \multirow[t]{2}{*}{ Agoraphobia sub-scale } & $t=9.26$ & $|4|$ & $<0.001$ & Agoraphobia: 24.2I & 12.439 to 19.195 \\
\hline & & & & Social phobia: 8.40 & \\
\hline \multirow[t]{2}{*}{ Social phobia sub-scale } & $t=-4.92$ & $|4|$ & $<0.001$ & Agoraphobia: 15.77 & -11.691 to -4.985 \\
\hline & & & & Social phobia: 24.11 & \\
\hline \multirow[t]{2}{*}{ Anxiety/depression sub-scale } & $t=1.92$ & 138 & 0.057 (NS) & Agoraphobia: 24.93 & -0.116 to 7.316 \\
\hline & & & & Social phobia: 21.33 & \\
\hline
\end{tabular}

Table 3 Age and problem severity of agoraphobia, social phobia and facially disfigured groups

\begin{tabular}{|c|c|c|c|c|c|}
\hline Comparison & Critical value & d.f. & Significance & Group means & $95 \% \mathrm{Cl}$ \\
\hline \multicolumn{6}{|c|}{ Facial disfigurement/agoraphobia groups } \\
\hline Age & & & & Agoraphobia: 40.70 & \\
\hline \multirow[t]{2}{*}{ Problem severity } & $t=-5.74$ & 176 & $<0.001$ & Facial disfigurement: 5.20 & -1.711 to -0.835 \\
\hline & & & & Agoraphobia: 6.47 & \\
\hline Gender & $\chi^{2}=6.93837$ & I & 0.00844 & 1 & - \\
\hline \multicolumn{6}{|c|}{ Facial disfigurement/social phobia groups } \\
\hline \multirow[t]{2}{*}{ Age } & $t=4.18$ & 178 & $<0.001$ & Facial disfigurement: 42.21 & 4.507 to 12.568 \\
\hline & & & & Social phobia: 33.68 & \\
\hline \multirow[t]{2}{*}{ Problem severity } & $t=-5.12$ & 178 & $<0.001$ & Facial disfigurement: 5.20 & -1.542 to -0.683 \\
\hline & & & & Social phobia: 6.31 & \\
\hline
\end{tabular}

I. These results indicated a difference in the overall proportions of males and females from those to be expected by chance. Visual inspection suggested that these differences were accounted for by the greater proportion of female facially disfigured people. 
although their greater social avoidance was unlikely to be clinically important. Numbers in the current study gave enough power to distinguish between the groups involved and did distinguish between patients with agoraphobia and patients with social phobia and between facially disfigured people and patients with agoraphobia. Thus we may be reasonably confident that the lack of difference between facially disfigured people and patients with social phobia points to a genuine similarity rather than a type 2 error. The differences between facially disfigured people and patients with agoraphobia also suggest that the similar scores of disfigured people and patients with social phobia are unlikely to be due to selecting disfigured people by their global problem severity score on the Fear Questionnaire.

\section{Role of fear and avoidance in social difficulty following facial disfigurement}

The similarities found suggest that the social difficulties reported by disfigured people (Macgregor, 1951, 1990; Rumsey, 1983; Malt \& Ugland, 1989) may be due to phobic anxiety specific to social situations rather than to more generalised anxiety. This supports a fear-avoidance formulation of their difficulties (Newell, 1991, 1998) based on Lethem et al's
(1983) model of exaggerated pain perception. The model proposes that the difficulties experienced by disfigured people in social situations are maintained primarily by fear of the responses of others to them in such situations and associated avoidances. Although there is ample evidence that the actual responses given to disfigured people in social situations are often negative, the model attempts to distinguish between those who develop psychological difficulty following disfigurement and those who do not, in much the same way as the Lethem et al (1983) account does for responses to chronic back pain and Slade's (1994) model of body image does for eating disorders. Although most disfigured people show no marked social avoidance or psychological difficulty, they probably have higher rates of such difficulties than the general population (Newell, 1998). Fearavoidance may explain why some people develop psychological problems after disfigurement. Difficulty and anxiety in social situations are the most frequent complaints by disfigured people (Macgregor, 1979; Rumsey, 1983). Moreover, in three surveys of dermatology patients, plastic surgery expatients and media-recruited disfigured people (Newell, 1998), subjects showed marked social avoidance on validated scales, a measure of body attitudes and avoidances owing to facial appearance, response to an open-ended question about

Table 4 Fear Questionnaire agoraphobia and social phobia sub-scales: comparisons between facially disfigured people and patients with phobia

\begin{tabular}{|c|c|c|c|c|}
\hline Comparison & Critical value & d.f. & Significance & Group means \\
\hline \multicolumn{5}{|c|}{ Facial disfigurement/agoraphobia groups' } \\
\hline \multirow[t]{2}{*}{ Agoraphobia sub-scale } & $F=52.24$ & I & 0.001 & Agoraphobia: 25.4 \\
\hline & & & & Facial disfigurement: 10.5 \\
\hline \multirow[t]{2}{*}{ Social phobia sub-scale } & $F=11.33$ & I & 0.001 & Agoraphobia: 16.32 \\
\hline & & & & Facial disfigurement: 19.55 \\
\hline \multirow[t]{2}{*}{ Anxiety/depression sub-scale } & $F=0.70$ & I & 0.404 (NS) & Agoraphobia: 25.68 \\
\hline & & & & Facial disfigurement: 20.06 \\
\hline \multicolumn{5}{|c|}{ Facial disfigurement/social phobia groups ${ }^{2}$} \\
\hline \multirow[t]{2}{*}{ Agoraphobia sub-scale } & $F=3.49$ & I & 0.063 (NS) & Social phobia: 8.8 \\
\hline & & & & Facial disfigurement: 10.5 \\
\hline \multirow[t]{2}{*}{ Social phobia sub-scale } & $F=0.081$ & I & 0.368 (NS) & Social phobia: 24.3 \\
\hline & & & & Facial disfigurement: 19.6 \\
\hline \multirow[t]{2}{*}{ Anxiety/depression sub-scale } & $F=2.78$ & I & 0.097 (NS) & Social phobia: 21.32 \\
\hline & & & & Facial disfigurement: 20.06 \\
\hline
\end{tabular}

I. Main effects of independent variables only shown. Within the analysis of covariance, these reflect the exclusion of the mediating influence of different levels of problem severity between the groups.

2. Main effects of independent variables only shown. Within the analysis of covariance, these reflect the exclusion of the mediating influence of different levels of problem severity and different ages between the groups.

avoidance and spontaneous comments. Against this background, the social difficulties of facially disfigured people seem to reflect considerable phobic anxiety.

\section{Clinical implications}

Our findings have treatment implications. Cognitive-behavioural therapy helps phobias in general, including social phobia (Fonagy \& Roth, 1996), and can help even with minimal therapist input (Newell, 1998). Given the large number of disfigured people and the likelihood that few are in contact with psychological services (Wallace, 1988), this is an important issue. A major initiative to reduce facially disfigured people's difficulties and evaluate the outcome (Robinson et al, 1996) uses much therapist time (at least a two-day 'foundation' workshop, with the possibility of further follow-up (Partridge et al, 1994)). More emphasis on exposure therapy might improve the value of this approach, but it would still be expensive given the large numbers of disfigured people in the community. It could be made more costeffective by trying the self-treatment approaches that have proved to be effective in phobic disorders.

If the present study's findings prove robust, such an approach could also help the prevention and early recognition and treatment of psychological difficulties of disfigured people. Preparation for surgery could stress the need to expose one's changed body part in social situations, as suggested, for example, by Newell (1991).

\section{Limitations and possible further work}

The study would have benefited from examination of a wider range of measures and an investigation of how far the disfigured subjects were in fact subjected to adverse comments from others. A structured interview to determine how far the disfigured subjects met established criteria for a diagnosis of social phobia would also have been useful. However, resource constraints did not allow the addition of these elements. A replication of the present study is required, and might include such components. Additionally, controlled studies of cognitive-behavioural self-treatment with minimal therapist input for the difficulties of disfigured people would be welcome, because the plight of this group has long been neglected. 


\section{REFERENCES}

Corney, R. H., Stanton, R., Newell, R., et al (1990) Comparison of progesterone, placebo and behavioura psychotherapy in the treatment of premenstrual syndrome. Journal of Psychosomatic Obstetrics and Gynaecology, II, 21I-220.

Faber, A. W., Klasen, H. J., Sauer, E. W., et al (1987) Psychological and social problems in burn patients after discharge. A follow-up study. Scandinavian Journal of Plastic and Reconstructive Surgery, 2I, 307-309.

Feigenbaum, W. (1981) A social training program for clients with facial disfigurations: a contribution to the rehabilitation of cancer patients. International journal of Rehabilitation Research, 4, 50I-509.

Fonagy, A. \& Roth, P. (1996) What Works for Whom. New York: Guilford.

Goldberg, D. \& Williams, P. (1991) A User's Guide to the General Health Questionnaire. Windsor: NFER-Nelson.

Gould, A. L. (1993) Sample sizes for even rate equivalence trials using prior information. Statistics in Medicine, 12, 2009-2023.

Houston, V. \& Bull, R. (1994) Do people avoid sitting next to someone who is facially disfigured? European Journal of Social Psychology, 24, 279-284.

Lethem, J., Slade, P. D., Troup, J. D. G., et al (1983) Outline of a fear-avoidance model of exaggerated pain perception - I. Behaviour Research and Therapy, 2I 40I-408.

Macgregor, F. C. (195I) Some psycho-social problems associated with facial deformities. American Sociological Review, 16, 629-638.

- (1979) After Plastic Surgery: Adaptation and Adjustment. New York: Praeger.

- (1989) Social, psychological and cultural dimensions of cosmetic and reconstructive plastic surgery. Aesthetic Plastic Surgery, I3, I-8.

_ (1990) Facial disfigurement: problems and management of social interaction and implications for mental health. Aesthetic Plastic Surgery, 14, 249-257.

Malt, U. (198I) Long-term psychosocial follow-up studies of burned adults: review of the literature. Burns, 6. 190-197.

_ \& Ugland, O. M. (1989) A long-term psychosocial follow-up study of burned adults. Acta Psychiatrica Scandinavica Supplementum, 355, 94-102.

Marks, I. M. \& Mathews, A. M. (1979) Brief standard self-rating for phobics. Behaviour Research and Therapy, 17, 263-267.

Martin, J., Meltzer, H. \& Elliot, D. (1988) Office of Population Censuses and Surveys Social Survey Division. Surveys of Disability in Great Britain, Report I: The Prevalence of Disability Among Adults. London: Office of Population Censuses and Surveys.

\section{CLINICAL IMPLICATIONS}

- Cognitive-behavioural therapy may be useful for facially disfigured people with difficulty in social situations because of their similarities to people with social phobia.

- The possibility of offering treatment via self-help packages suggests that considerable numbers may be offered treatment cost-effectively.

- Advice stressing exposure therapy and social contact may be useful as part of preparation for surgery.

\section{LIMITATIONS}

- A broader range of measures would have offered the opportunity for further comparisons between people with phobia and disfigured people.

- Stigma is an important issue in disfigurement but was not examined in the present study.

- Establishing the extent to which disfigured people meet the diagnostic criteria for social phobia may be valuable.

ROBERT NEWELL, PhD, School of Healthcare Studies, University of Leeds, Leeds; ISAAC MARKS, FRCPsych, Institute of Psychiatry, London

Correspondence: R. Newell, School of Healthcare Studies, University of Leeds, 22 Hyde Terrace, Leeds LS2 9LN

(First received 8 June 1999, final revision 7 September 1999, accepted 10 September 1999)

Munro, B. H. \& Page, E. B. (1993) Statistical Methods for Health Care Research (2nd edn). Philadelphia, PA: Lippincott.

Newell, R. (1991) Body image disturbance: cognitive-behavioural formulation and intervention. journal of Advanced Nursing, 16, 1400-1405.

- (1998) Facial Disfigurement and Avoidance: A Cognitive-Behavioural Approach. PhD thesis, University of Hull.

Partridge, J., Coutinho, W., Robinson, E., et al (1994) Changing faces: two years on. Nursing Standard, 34, $54-58$

Robinson, E., Rumsey, N. \& Partridge, J. (1996) An evaluation of the impact of social interaction skills training for facially disfigured people. British Journal of Plastic Surgery, 49, 28I-289.
Rumsey, N. (1983) Psychological Problems Associated with Facial Disfigurement. PhD thesis, North East London Polytechnic.

Senn, S. (1993) Inherent difficulties with active control equivalence studies. Statistics in Medicine, $\mathbf{1 2}$, 2367-2375

Slade, P. D. (1994) What is body image? Behaviour Research and Therapy, 32, 497-502.

Snaith, R. P. \& Zigmond, A. S. (1994) The Hospital Anxiety and Depression Scale Manual.Windsor: NFERNelson.

Wallace, L. A. (1988) Abandoned to a social death. Nursing Times, 84, 34-37.

Williams, E. E. \& Griffiths, T. A. (1991) Psychological consequences of burn injury. Burns, $17,478-480$. 